\title{
An Empirical Study on the Interaction between Comprehensive Transportation Accessibility and County Economic Development
}

\author{
Xuan Zhou \\ School of Economics, Sichuan University, Chengdu 610065, China
}

\begin{abstract}
The county economy is the foundation of the regional economic development of our country, and there is an interactive mechanism between the comprehensive transportation accessibility and the county economic development level. Based on the comprehensive accessibility and economic development level, the 136 counties and county-level cities in Sichuan Province can be divided into high-accessibility counties, medium-accessibility counties, low-accessibility counties, high-economic-development-level counties, medium-economicdevelopment-level counties and low-economic-development-level counties. And all these counties could also be divided into 9 types by respectively combining two of them. This paper analyzed the interactive relationship and divided 136 counties into 3 main types, (synchronous county, leading county and lagging county), and then puts forward some development countermeasures.
\end{abstract}

Keywords-county economy; comprehensive transportation accessibility; interaction measurement

\section{INTRODUCTION}

German economist Johan Heinrich von Thunen (1783-1850) first studied the distance between production location and consumption location and the layout of agricultural production. The American scholar W. G. Hansen proposed the concept of accessibility in 1959 and used gravity model to study the relationship between accessibility and land use. Based on the accessibility analysis method, this paper takes Sichuan province as an example and focuses on the interaction between regional accessibility (rather than node accessibility) and county economy development under the comprehensive transportation mode.

\section{RESEARCH METHOD}

\section{A. County Comprehensive Transportation Accessibility Measurement}

By referring to Hansen's gravity model [1] and domestic related research ${ }^{[2]-[6]}$, the comprehensive traffic accessibility measurement index factor $(\mathrm{Z})$ is obtained by combining the current situation of Sichuan, including county connectivity $\operatorname{index}\left(f_{1}\right)$, county external accessibility index $\left(f_{2}\right)$, and location relationship index between county and central city $\left(f_{3}\right)$. The formula can be expressed as:

$$
\mathrm{Z}=\sum_{\mathrm{i}=1}^{3} \mathrm{a}_{\mathrm{i}} \mathrm{f}_{\mathrm{i}}
$$

In formula (1): $\mathrm{f}_{\mathrm{i}}$ represents the value of each indicator factor, and $\mathrm{a}_{\mathrm{i}}$ represents the weight coefficient of each indicator factor. Combined with the relevant studies ${ }^{[3]-[6]}$ and the comprehensive transportation situation in Sichuan province and relevant experts' opinions, the three index factors are assigned as $0.3,0.4$ and 0.3 respectively.

(1) The county connectivity index $\left(f_{1}\right)$ depends on the density of the transportation network in the county area, and most of the transportation in the county area is realized by road transportation. Therefore, the density of the high-level highway network in the county area is the core index reflecting the collection convenience of people and material flow.

The following criteria are formulated by referring to the hierarchical valuation methods of Jin Fengjun et al ${ }^{[2]}$, Huang Xiaoyan et al ${ }^{[7]}$.

$$
\mathrm{f}_{1}(\mathrm{x})=\left\{\begin{array}{lr}
0.5 & x<0.5 \\
1 & 1>x \geq 0.5 \\
1.5 & 1.5>x \geq 1 \\
2 & 2>x \geq 1.5 \\
2.5 & x \geq 2
\end{array}\right.
$$

In formula (2): ${ }^{\mathrm{x}}$ represents the road network density of the county, (unit: $\mathrm{km} / \mathrm{km}^{2}$ ), including the I-IV high-level highway, excluding the rural normal highway.

(2) The county external accessibility index $\left(f_{2}\right)$ measures the convenience of a county's external economic and social communication. The higher the county's external accessibility is, the stronger the influence of the county's external traffic on economic development is. The influence of different transportation modes on the external accessibility of counties is very different. In the calculation, it must take into account the location of stations, ports, airports and the grade of roads and railway stations. The specific indicators refer to the relevant studies of Liu Chuanming et al. ${ }^{[2]}$ and Jin Fengjun et al. ${ }^{[5]}$, which were revised as shown in Table 1 below. 
TABLE I. CLASS CLASSIFICATION AND ASSIGNMENT OF THE COUNTY EXTERNAL ACCESSIBILITY INDEX

\begin{tabular}{|c|c|c|}
\hline Number & Classification & Assignment \\
\hline 1 & Special train station & 3 \\
\hline 2 & $\begin{array}{l}\text { Within } 30 \mathrm{~km} \text { of the special train station; } \\
\text { First-class train station; highway } \\
\text { entrance and exit; One-level national } \\
\text { road }\end{array}$ & 2.5 \\
\hline 3 & $\begin{array}{l}\text { Within } 60 \mathrm{~km} \text { of the special train station; } \\
\text { Within } 30 \mathrm{~km} \text { of the first-class train } \\
\text { station; Second-class train station; } \\
\text { Trunk and branch line airport; Within } \\
30 \mathrm{~km} \text { of the highway entrance and exit; } \\
\text { One-level provincial road; Main port }\end{array}$ & 2 \\
\hline 4 & $\begin{array}{l}\text { Within } 60 \mathrm{~km} \text { of the first-class train } \\
\text { station; Within } 30 \mathrm{~km} \text { of the second-class } \\
\text { train station; Tertiary train station; } \\
\text { Within } 60 \mathrm{~km} \text { of the highway entrance } \\
\text { and exit; The worst sections of the } \\
\text { national road are grade two, three or } \\
\text { four; The worst sections of the } \\
\text { provincial road are grade two; Within } \\
30 \mathrm{~km} \text { of the main port; Important port }\end{array}$ & 1.5 \\
\hline 5 & $\begin{array}{l}\text { Within } 60 \mathrm{~km} \text { of the second-class train } \\
\text { station; Within } 30 \mathrm{~km} \text { of the tertiary train } \\
\text { station; Fourth-class train station; } \\
\text { Within } 30 \mathrm{~km} \text { of the trunk line airport; } \\
\text { Branch line airport; The worst sections } \\
\text { of the provincial road are grade three; } \\
\text { Within } 60 \mathrm{~km} \text { of the main port; Within } \\
30 \mathrm{~km} \text { of the important port; General } \\
\text { port }\end{array}$ & 1 \\
\hline 6 & $\begin{array}{l}\text { Within } 60 \mathrm{~km} \text { of the tertiary train station; } \\
\text { Within } 30 \mathrm{~km} \text { of the fourth-class train } \\
\text { station; The worst sections of the } \\
\text { provincial road are grade four }\end{array}$ & 0.5 \\
\hline 7 & Else cases & 0 \\
\hline
\end{tabular}

(3) The location relationship index between county and central city $\left(f_{3}\right)$ depends on the radiation and influence of central city on county, and is affected by the size of central city, county scale and the distance between them. The location relationship index between county and central city can be defined as:

$$
\begin{gathered}
\mathrm{f}_{3}=\phi_{1} \times \phi_{2} \\
\varphi_{1}= \begin{cases}2 & \mathrm{x}<30 \\
1.5 & 30 \leq \mathrm{x}<60 \\
1 & \mathrm{x} \geq 60\end{cases} \\
\Phi_{2}=\frac{\sqrt{\mathrm{G \times P}}}{\sqrt{\mathrm{G}_{0} \times P_{0}}}
\end{gathered}
$$

In formula (3)(4)(5), $\Phi_{1 \text { and }} \Phi_{2}$ respectively represents the distance index between the county and the central city, and the influence index of the central city to the county. $\mathrm{G}, \mathrm{P}, \mathrm{G}_{0}$ and $P_{0}$, respectively, indicate the GDP and population scale of the central city to which the county is attached, and the average GDP and population scale of all central cities. ${ }^{X}$ represents the distance between the county center and the central city. It's divided into three intervals according to the nodes of $30 \mathrm{~km}$ and $60 \mathrm{~km}$. The central city is the provincial capital city or prefecture-level city where the county is located. A county without its central city, the $\phi_{2}$ value is 0 .

\section{B. County Economic Development Level Measurement}

Based on the current situation and development stage of Sichuan, this paper selects the per capita GDP (X1), per capita fiscal income(X2), per capita social fixed assets investment(X3), tertiary industry proportion(X4), per capita gross industrial output value(X5), urbanization rate(X6), employment rate(X7), the total retail amount of social consumer goods per capita (X8). These indicators are used to calculate the economic development level of counties(Y) by using the comprehensive index method.

\section{EMPIRICAL ANALYSIS}

\section{A. Analysis on County Comprehensive Transportation Accessibility}

The highest of 136 counties in Sichuan is Shuangliu (12.40), 36.42 times that of the lowest. Counties can be divided into three categories: high accessibility, medium accessibility and low accessibility, as shown in Table 2 . The high-accessibility counties account for $11.76 \%$ of the total number of counties, and the distribution is concentrated in the Chengdu Plain Economic Zone, and less in the Southern Sichuan Economic Zone. The medium-accessibility counties account for $38.24 \%$, mainly distributed along the three major transportation trunk lines (Chengdu-Mianyang-Leshan, Chengdu-SuiningGuang'an-Dazhou and Chengdu-Ziyang-Neijiang-ZigongYibin) and less in Panxi area. Low-accessibility counts account for $50 \%$, mainly distributed in ethnic areas, mountainous areas such as Bazhong and Ya'an, as well as areas far from central cities such as the south of Leshan and the south of Yibin.

TABLE II. ANALYSIS OF COUNTY COMPREHENSIVE TRAFFIC ACCESSIBILITY CLASSIFICATION

\begin{tabular}{ccccc}
\hline Classification & $\begin{array}{c}\text { Accessibility } \\
\text { interval }\end{array}$ & $\begin{array}{c}\text { Numb } \\
\text { er }\end{array}$ & $\begin{array}{c}\text { County } \\
\text { GDP per } \\
\text { capita (100 } \\
\text { million } \\
\text { yuan) }\end{array}$ & $\begin{array}{c}\text { County } \\
\text { area } \\
\text { ratio } \\
(\%)\end{array}$ \\
\hline $\begin{array}{c}\text { High- } \\
\text { accessibility }\end{array}$ & $(5.00,12.39)$ & 16 & 240.52 & $3.88 \%$ \\
\hline $\begin{array}{c}\text { Medium- } \\
\text { accessibility }\end{array}$ & $(3.00,5.00)$ & 52 & 154.96 & $21.87 \%$ \\
\hline $\begin{array}{c}\text { Low- } \\
\text { accessibility }\end{array}$ & $(0.35,3.00)$ & 68 & 40.40 & $74.25 \%$ \\
\hline
\end{tabular}

B. Analysis of County Economic Development Level

Results of the comprehensive exponential method show the highest level of economic development is Xinjin county (0.94), and the lowest is Meigu county (0.16). There are more economically strong counties in Chengdu plain economic zone. Among bottom ten, 9 are in Ganzi and Liangshan, and 1 is in mountainous area of southern Sichuan. According to the economic development level, counties of Sichuan can be divided into high, middle and low levels, as is reflected in 
Table 3, and the range of grade distribution is quite different. There are few counties, as less as 16 , with high economic development level, only 3 of which have level above 0.8 . The county with medium economic development level is the most, accounting for $42.65 \%$, with little difference in levels. The number of county with low economic development level is close to that of county with medium level, and the number of counties with level in the range $(0.3,0.4)$ is relatively large, reaching 32. From the view of spatial layout, most counties with high level of economic development are distributed in the area along the Chengdu-Mianyang-Leshan railway, and a few are in Panxi, southern Sichuan and other areas. Counties with medium economic development level are mainly distributed in the area along the Chengdu-Mianyang-Leshan railway, southeast Sichuan and southwest Sichuan. Counties with low economic development level are mainly distributed in Ganzi, Aba, Liangshan and Qinba mountains in northeast Sichuan.

TABLE III. THE COMPARATIVE ANALYSIS OF COUNTY ECONOMIC DEVELOPMENT LEVEL BY GRADE

\begin{tabular}{ccccc}
\hline & & & \multicolumn{2}{c}{$\begin{array}{c}\text { Proportion in 136 } \\
\text { counties }\end{array}$} \\
\cline { 4 - 5 } Classification & $\begin{array}{c}\text { Economic } \\
\text { developme } \\
\text { nt interval }\end{array}$ & $\begin{array}{c}\text { Numb } \\
\text { er }\end{array}$ & $\begin{array}{c}\text { Area } \\
\text { proportion } \\
(\%)\end{array}$ & $\begin{array}{c}\text { Populati } \\
\text { on } \\
\text { proporti } \\
\text { on } \\
(\%)\end{array}$ \\
\hline $\begin{array}{c}\text { High economic } \\
\text { development } \\
\text { level }\end{array}$ & $\begin{array}{c}(0.600, \\
0.941)\end{array}$ & 24 & 12.12 & 17.58 \\
\hline $\begin{array}{c}\text { Medium } \\
\text { economic } \\
\text { development } \\
\text { level }\end{array}$ & $\begin{array}{c}(0.400, \\
0.600)\end{array}$ & 58 & 37.13 & 41.00 \\
\hline $\begin{array}{c}\text { Low economic } \\
\text { development } \\
\text { level }\end{array}$ & $\begin{array}{c}\text { (0.162, } \\
0.400)\end{array}$ & 54 & 50.75 & 41.42 \\
\hline
\end{tabular}

C. The Interaction between the Comprehensive Transportation Accessibility and the Economic Development of a County

Through the case study above, the interaction between the comprehensive transportation accessibility and the economic development of a county can be summarized as follows. The letter A means high economic development level but low comprehensive transportation accessibility. The letter B means high economic development level but medium comprehensive transportation accessibility. The letter $\mathrm{C}$ means high economic development level and high comprehensive transportation accessibility. The letter D means medium economic development level but low comprehensive transportation accessibility. The letter $\mathrm{E}$ means medium economic development level and medium comprehensive transportation accessibility. The letter $\mathrm{F}$ means medium economic development level but high comprehensive transportation accessibility. The letter $\mathrm{G}$ means low economic development level and low comprehensive transportation accessibility. The letter $\mathrm{H}$ means low economic development level but medium comprehensive transportation accessibility. The letter I means low economic development level but high comprehensive transportation accessibility. These 9 types are combined into three main types, synchronous county (CEG), leading county (FHI) and lagging county (ABD). The economic development level and comprehensive transportation development of CEG have a considerable coordination. In FHI, comprehensive transportation has no obvious effect on county economy development. The comprehensive transportation development of $\mathrm{ABD}$ cannot catch up with the county economy development level.

TABLE IV. THE REGIONAL DISTRIBUTION OF CEG, FHI AND ABD

\begin{tabular}{|c|c|c|c|c|c|c|c|c|c|}
\hline & \multicolumn{2}{|c|}{ Plain county } & \multicolumn{2}{|c|}{ Hilly county } & \multicolumn{2}{|c|}{$\begin{array}{l}\text { Mountainous } \\
\text { county }\end{array}$} & \multicolumn{2}{|c|}{$\begin{array}{l}\text { County in ethnic } \\
\text { minority area }\end{array}$} & \multirow{2}{*}{ Total } \\
\hline & Number & $\begin{array}{c}\text { Proport } \\
\text { ion }\end{array}$ & Number & $\begin{array}{l}\text { Proport } \\
\text { ion }\end{array}$ & Number & $\begin{array}{c}\text { Proport } \\
\text { ion }\end{array}$ & Number & $\begin{array}{l}\text { Proport } \\
\text { ion }\end{array}$ & \\
\hline CEG & 9 & $60 \%$ & 23 & $52.3 \%$ & 9 & $34.6 \%$ & 29 & $56.9 \%$ & 70 \\
\hline FHI & 3 & $20 \%$ & 17 & $38.6 \%$ & 3 & $11.5 \%$ & 1 & $1.9 \%$ & 24 \\
\hline $\mathrm{ABD}$ & 3 & $20 \%$ & 4 & $9.1 \%$ & 14 & $53.9 \%$ & 21 & $41.2 \%$ & 42 \\
\hline Total & 15 & $100 \%$ & 44 & $100 \%$ & 26 & $100 \%$ & 51 & $100 \%$ & 136 \\
\hline
\end{tabular}


The proportion of CEG, FHI and ABD in Sichuan counties is $51.47 \%, 15.65 \%$ and $30.88 \%$ respectively, as shown in Table 4. From the view of regional distribution, most CEG are in hilly area and ethnic minority area, accounting for $74.3 \%$ in all $\mathrm{CEG}$, and $9 \mathrm{CEG}$ are in plain and mountainous area. FHI are mainly in hill area, accounting for $70.8 \%$ in all FHI. 3 FHI are in plain and mountainous area and only 1 is in ethnic minority area. ABD are mainly distributed in mountainous area and ethnic minority area, accounting for $83.3 \%$ in all ABD. There are $3 \mathrm{ABD}$ in plain and $4 \mathrm{ABD}$ in hilly area.

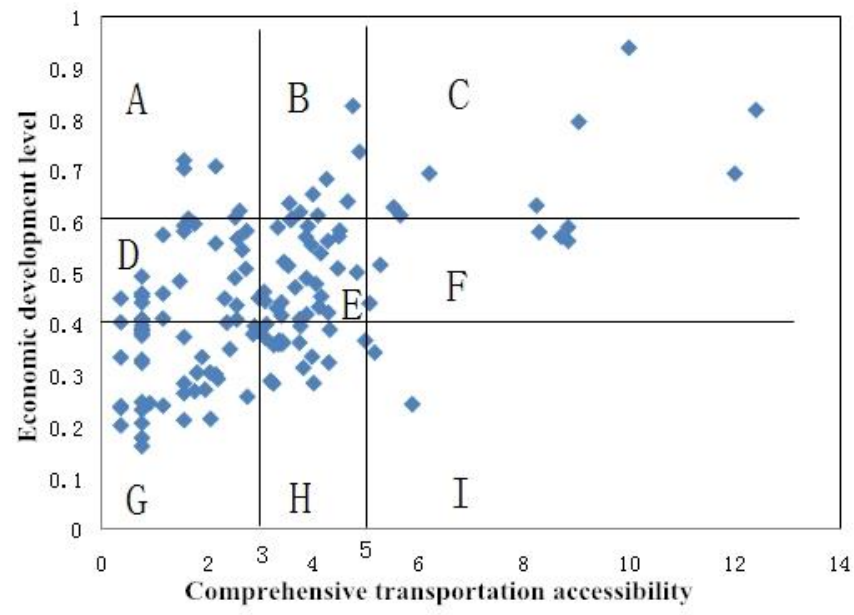

FIGURE I. THE COMBINATION RELATIONSHIP BETWEEN COMPREHENSIVE TRANSPORTATION ACCESSIBILITY AND ECONOMIC DEVELOPMENT LEVEL

Linearly fit the comprehensive transportation accessibility and economic development level of a county via Eview6.0, and the following formula can be obtained. $y=0.58 x+0.24$, where $y$ is the economic development level, $\mathrm{x}$ is the comprehensive transportation accessibility. The correlation between $\mathrm{x}$ and $\mathrm{y}$ reaches 0.58, which shows the significance of the comprehensive transportation development to the economic development level of a county. As is reflected in Fig. 1, the comprehensive transportation accessibility and economic development level are mainly distributed in type D, E, G and $\mathrm{H}$. There are more $\mathrm{G}$ and less $\mathrm{C}$, and the contrast between the two is large. Counties of type D, E, G and $\mathrm{H}$ hold $83.82 \%$ of all. There are only 8 type $\mathrm{C}$ counties, located near highways and railways, 6 of which belong to Chengdu. The largest number is type $\mathrm{G}$, which has 36 counties and holds $26.5 \%$. 28 of them are in Aba, Ganzi and Liangshan, and others are scattered in mountainous areas in southern and eastern Sichuan. They are characterized with lack of trunk railways, highways and high grade roads passing by county areas. And they are also far away from big cities and aviation centers.

\section{CONClusions AND SUGGeStions}

There is a positive correlation in counties of Sichuan between the accessibility of comprehensive transportation and the development level of economy, and both have obvious spatial differences. The comprehensive transportation accessibility has certain coordination with the development level of economy. Via the above analysis on the comprehensive transportation accessibility, the development level of economy and the relationship between the two, conclusions can be drawn as follows.

Firstly, the comprehensive transportation accessibility has certain coordination with the development level of economy in counties and counties with synchronous development account for $51.47 \%$ of all counties in Sichuan. Secondly, the comprehensive transportation accessibility of a county is quite different from the single transportation accessibility, so is the development level of county economy from pure GDP or GDP per capita. The comprehensive transportation accessibility of a county reflects a county's traffic, location and central city's radiation to the county. And the economic development level of a county based on the comprehensive index method can reflect the economic development, urbanization, social service, consumption and other relevant data of a county, revealing the overall social appearance of a county. Thirdly, by means of the analysis on types of counties which is a novel development strategy by Sichuan province, the economic development and comprehensive transportation accessibility of counties belonging to the same county-like areas are similar. There are 8 counties with high economic development level and high accessibility, 6 of which are in plain area. On the other hand, there are 36 counties with low economic development level and low accessibility, 28 of which are in ethnic minority area and take up 54.9\% of all ethnic minority areas. Fourthly, the comprehensive traffic accessibility of counties in Sichuan is ranked from high to low as follows.

A (plain county) $>$ A (hilly county) $>$ A (mountainous county) $>$ A (county in ethnic minority area)

The stepwise difference of comprehensive traffic accessibility in four types of county is obvious. The economic development level of counties in Sichuan is ranked from high to low as follows.

A (plain county) $>$ A (hilly county) $\approx A$ (mountainous county) $>$ A (county in ethnic minority area)

The economy of plain counties has developed significantly while it in ethnic minority area is relatively poor. The overall economic development of hilly counties and mountainous counties is close.

Based on the analysis above, the author holds the comprehensive transportation accessibility is a ladder for both inward and outward development of a county and the economic development scale is the foundation of a county's take-off. Reasonable planning and coordination between the two is the key to the development of county economy. What's crucial in coordinating the development of comprehensive transportation and county economy is adjusting measures to local conditions, divisional tactics and classified implementation. For counties in different areas, the point-axis spatial unbalanced development strategy should be adopted according to the spatial distribution law of comprehensive transportation accessibility and economic development level. 


\section{ACKNOWLEDGMENTS}

This paper is completed with the assistance from Doctor Dunyou Shi and anonymous reviewers also help improve the initial manuscript.

\section{REFERENCES}

[1] Walter G. Hansen, "How Accessibility Shapes Land Use. Journal of the American Institute of Planners," Phil. Trans. Roy. Soc. London, vol. 25 (2), pp. 73-76, 1959.

[2] Fengjun Jin, Chengjin Wang, Xiuwei Li, "Screening methods and application analysis of regional traffic advantages in China," vol. 63 (8), 2008, pp.787-798. ( Chinese journal)

[3] Yu Cheng, Lei Liu, Jianlan Ren, Fengbo Lai, "Research on accessibility, economic development level measurement and spatial pattern of urban traffic in Jinan," vol. 33 (3), 2013, pp.59-64. ( Chinese journal)

[4] Yu Cheng, Lei Liu, Jianlan Ren, Fengbo Lai, "Study on comprehensive transportation accessibility, economic development level measurement and spatial pattern of counties -- a quantitative analysis of 91 counties in Shandong province," vol. 33 (9), 2013, pp.1058-1065. ( Chinese journal)

[5] Chuanming Liu, Juxin Zeng, "County comprehensive transportation accessibility measurement and its relationship with the level of economic development -- a quantitative analysis of 79 counties in Hubei province," vol. 30 (12), 2011, pp.2210-2222. ( Chinese journal)

[6] Zhixue Zhang, "Study on the evolution of regional accessibility and its relationship with regional economic development -- a case study of Shanxi province," unpublished.

[7] Xiaoyan Huang, Xiaoshu Cao, Tao Li, "The relationship between regional traffic superiority and economic development in Hainan,"vol. 30 (6), 2011, pp.985-999. ( Chinese journal) 